\title{
Interaksi Obat Antara Klopidogrel dan Proton Pump Inhibitor (PPI)
}

\author{
Ni Made Amelia Ratnata Dewi ${ }^{1}$ \\ ${ }^{1}$ Program Studi Farmasi, Universitas Mataram, Mataram, Indonesia
}

\section{Article Info}

Received : 22 Maret 2020

Revised : 24 Maret 2020

Accepted: 8 April 2020

\begin{abstract}
The used of Proton Pump Inhibitor (PPI) could reduce the incidence of gastric bleeding in patients receiving dual antiplatelet therapy clopidogrel and aspirin. However clopidogrel is activate through a metabolic process by CYP2C19 meanwhile PPI is metabolized and inhibits CYP2C19. Pharmacodynamic studies show the effect of PPI especially omeprazole on clopidogrel metabolism, which can result in decreased effects of platelet inhibition. Some clinical studies have found that there are no events that can cause problems in the heart (cardiovascular event) if both drugs are given simultaneously. The clinical significance of drug interactions from clopidogrel and PPI is not yet clearly known but for safety it is recommended to limit the use of PPIs especially omeprazole. Another option is to replace PPI with H2 blockers or use PPI classes that are not much metabolized by CYP2C19 enzymes such as pantoprazole
\end{abstract}

Keywords: Drugs Interactio, clopidogrel, proton pump inhibitor

Citation:

Dewi, N.M.A.R. (2020). Interaksi Obat Antara Klopidogrel dan Proton Pump Inhibitor (PPI). Sasambo Journal of Pharmacy, 1(1), 1-5.

\section{Pendahuluan}

Kombinasi dual terapi antiplatelet yaitu aspirin dan klopidogrel untuk pencegahan cardiovascular ischemic events berulang telah terbukti efektif secara klinis pada banyak pasien (Tantry et al., 2011). Penggunaan kombinasi terapi antiplatelet jangka panjang dapat memicu terjadinya komplikasi perdarahan saluran pencernaan (Bhatt et al., 2010). Beberapa penelitian Randomized controlled Trial (RCT) menunjukkan bahwa penggunaan Proton Pump Inhibitor (PPI) dapat menurunkan terjadinya perdarahan gastrointestinal berulang pada pasien yang menerima aspirin (Lai et al., 2002). Namun studi farmakodinamik menunjukkan adanya efek PPI terhadap metabolisme klopidogrel yang dapat mengakibatkan penurunan efek dari inhibisi platelet.

\section{Mekanisme Antiplatelet Menyebabkan Gangguan pada Saluran Pencernaan \\ Antiplatelet bekerja dengan menginhibisi prostaglandin sehingga akibat penghambatan produksi tromboxane $\mathrm{A}_{2}$ (Bhatt et al., 2008).}

Prostaglandin bertanggung jawab terhadap peningkatan aliran darah pada mukosa, proliferasi dari sel epitel lambung dan menstimulasi sekresi dari mukus serta bicarbonat. Adanya hambatan terhadap sintesis prostaglandin oleh aspirin menurunkan efek proteksi mukosa lambung dan mengakibatkan lebih mudahnya terbentuk ulkus pada lambung karena asam endogen, pepsin dan garam empedu (Bhatt et al., 2008). Pada CURE trial didapatkan penggunaan terapi pada sindrom koroner akut dengan penambahan klopidogrel pada terapi aspirin meningkatkan rasio perdarahan saluran cerna hingga 85\% (Peters et al., 2003). Pada penelitian lain didapatkan kejadian perdarahan saluran cerna pada $1,1 \%$ pasien per tahun yang mendapatkan dual terapi antiplatelet jika dibandingkan dengan dengan pasien yang hanya mendapatkan aspirin (Peters et al., 2007)

\section{Mekanisme Interaksi Klopidogrel dan PPI}

Klopidogrel merupakan prodrug yang harus dimetabolisme di hati sehingga dapat memberikan 
efek antiagregasi. Klopidogrel diabsorbsi pada usus kemudian dimetabolisme melalui 2 jalur secara kompetitif di hati. Pada jalur pertama klopidogrel diabsorbsi secara cepat oleh karboksil-esterase 1 menjadi metabolit tidak aktif (Farid et al., 2010). Pada jalur metabolisme kedua klopidogrel dikonversi melalui dua tahap, tahap pertama menjadi 1-oxoklopidogrel oleh CYP2C19, CYP1A2 dan CYP2B6 kemudian menjadi metabolit aktifnya yaitu R-130964 pada tahap kedua (Farid et al., 2010).

Tabel 1. Metabolisme golongan PPI oleh enzim CYP (Drug Information Handbook, 2013)

\section{PPI Metabolisme}

\begin{tabular}{|c|c|}
\hline Omeprazole & $\begin{array}{l}\text { Substrat: CYP2A6 (minor), } \\
\text { 2C9 (minor), 2C19 (mayor), 2D6 } \\
\text { (minor), 3A4 (mayor) } \\
\text { Menghambat: CYP1A2 (lemah), } \\
\text { 2C9 (sedang), 2C19 (kuat), 2D6 } \\
\text { (lemah), 3A4 (lemah) } \\
\text { Menginduksi: CYP1A2 (lemah) }\end{array}$ \\
\hline Pantoprazole & $\begin{array}{l}\text { Substrat: CYP2C19 (mayor), } \\
\text { 2C9 (minor), 2D6 (minor), 3A44 } \\
\text { (minor) } \\
\text { Menghambat: CYP2C9 (lemah) } \\
\text { Menginduksi: CYP1A2 (lemah), } \\
\text { 3A4 (lemah) }\end{array}$ \\
\hline Lansoprazole & $\begin{array}{l}\text { Substrat: CYP2C9 (minor), } \\
\text { 2C19 (mayor), 3A4 (mayor) } \\
\text { Menghambat: CYP2C9 (lemah), } \\
\text { 2C19 (sedang), 2D6 (lemah), 3A4 } \\
\text { (lemah) } \\
\text { Menginduksi: CYP1A2 (lemah) }\end{array}$ \\
\hline Esomeprazole & $\begin{array}{lr}\text { Substrat: } & \text { CYP2C19 (mayor), } \\
\text { 3A4 (mayor) } & \\
\text { Menghambat: } & \text { CYP2C19 } \\
\text { (sedang) } & \\
\text { Menginduksi: } & -\end{array}$ \\
\hline Rabeprazole & $\begin{array}{l}\text { Substrat: } \\
\text { (mayor), 3A4; } \\
\text { Menghambat: CYP2C8 (sedang), } \\
\text { 2C19 (sedang), 2DC (lemah), } \\
\text { 3A4 (lemah) } \\
\text { Menginduksi: - }\end{array}$ \\
\hline
\end{tabular}

Proton pump inhibitor (PPI) merupakan derivat prodrugs benzimidazole yang absorbsinya pada saluran pencernaan dipengaruhi oleh pglikoprotein transporter (Tantry et al., 2011). $\mathrm{H}^{+} / \mathrm{K}^{+}$ adenosin trifosfatase (ATPase) berada pada membran kanalikular pada sel parietal lambung mengsekresi asam klorida dan proton yang menukar kalium dengan uraian ATP (Tantry et al., 2011). Setelah diabsorbsi PPI diaktivasi, sulfonamid siklik yang teraktivasi akan berikatan secara kovalen dengan dengan sistein ekstrasitoplasma yang merupakan residu dari $\mathrm{H}^{+} / \mathrm{K}^{+}$ATPase dan menghambat aktivitas pompa proton/ sekresi asam lambung (Tantry et al., 2011). PPI sangat efektif untuk menghambat sekresi asam lambung, namun adanya perbedaan farmakokinetik dan farmakodinamik dari obat-obat ini dapat mempengaruhi efek klinik serta memiliki potensi terjadinya interaksi obat (Ogawa \& Echizen, 2010). Semua obat golongan PPI selain rabeprazol dimetabolisme dan secara kompetitif menghambat CYP2C19 and CYP3A4 (Ieiri et al., 2005). Lansoprazole dan omeprazole merupakan inhibitor terkuat $(\mathrm{Ki}=0.4$ to $1.5 \mu \mathrm{mol} / 1$ dan 2 to $6 \mu \mathrm{mol} / \mathrm{l})$ sedangkan pantoprazole merupakan inhibitor terlemah dari CYP2C19 $(\mathrm{Ki}=14$ to $69 \mu \mathrm{mol} / \mathrm{l})$ (Ogawa \& Echizen, 2010).

\section{Interaksi Obat Secara Farmakodinamik Antara Klopidogrel dan PPI}

Klopidogrel dapat memberikan efek antiplatelet dengan cara membentuk ikatan yang dapat menginaktivasi ikatan disulfida dengan platelet reseptor P2Y12 ADP. Klopidogrel menghambat efek ADP pada reseptor P2Y12 (Gilard et al., 2008). Hal ini diasosiakan dengan adanya defosforilasi intraplatelet melalui stimulasi vasodilator fosfoprotein/ vasodilator-stimulated phosphoprotein (VASP). Proses fosforilasi dari vasodilator-stimulated phosphoprotein dapat menggambarkan indeks reaktivitas klopidogrel terhadap platelet. Semakin tinggi indeks reaktivitas platelet/platelet index reactivity (PRI), maka semakin sering terjadi trombosis akibat klopidogrel (Barragan et al., 2003).

Gilard et al., pada OCLA study tahun 2008 mendapatkan bahwa omeprazole secara signifikan dapat menurunkan efek inhibisi platelet dari klopidogrel jika diberikan bersama omeprazole dengan melihat nilai PRI dari hari pertama hingga hari ke-7. Hari I pertama didapatkan nilai PRI adalah 83,2\% dan 83,9\% pada kelompok plasebo dan pemberian omeprazole. Pada hari ke-7 didapatkan nilai PRI sebesar 39,8 dan 51,4\% pada kelompok plasebo dan omeprazol. Hal ini mengindikasikan terdapat pnurunan aktivitas antiagregasi platelet pada kelompok yang diberikan omeprazole (Gilard et al., 2008).

Pada PACA study tahun 2009 sebanyak 109 pasien yang mendapatkan klopidogrel setelah menjalani coronary stenting akibat non-ST-segment elevation acute coronary syndrome (NSTE ACS) diberikan omeprazole dan pantoprazole secara acak (Cuisset et al., 2009). Platelet reactivity index (PRI) 
vasoactive stimulated phosphoprotein (VASP) digunakan untuk melihat efek klopidogrel. Setelah 1 bulan pasien yang menggunakan pantoprazole didapatkan efek klopidogrel yang lebih baik jika dibandingkan dengan omeprazole dengan nilai VASP/PRI yang lebih rendah pada pantoprazole $(36 \% \pm 20 \%$ vs $48 \%$ $\pm 17 \%, P=0.007)$. Hal ini menunjukkan bahwa pantoprazole memiliki efek yang kurang poten terhadap CYP2C19 inhibitor, sehingga efeknya terhadap efektivitas klopidogrel lebih rendah jika dibandingkan dengan omeprazole (Cuisset et al., 2009).

Sibbing et al., (2009) meneliti tentang efek beberapa obat golongan PPI (omeprazole, pantoprazole dan esomeprazole) terhadap respon klopidogrel dengan platelet. Sebanyak 1000 pasien yang menjalani coronary angiography diukur dengan Adenosine diphosphate (ADP)-induced platelet aggregation (dalam $\mathrm{AU}^{*}$ menit). Sebanyak 268 pasien menggunakan PPI, (pantoprazole, $n=162$; omeprazole, $\mathrm{n}=64$; esomeprazole, $\mathrm{n}=42$ ). Agregasi platelet ditemukan lebih tinggi pada pasien yang menggunakan omeprazole (295.5 [193.5-571.2] $\mathrm{AU}^{*}$ menit) jika dibandingkan dengan pasien yang tidak diterapi PPI (220.0 [143.8-388.8] AU*min; $\mathrm{p}=0.001)$. Agregasi platelet pada pasien yang diterapi pantoprazole (226.0 [150.0-401.5] $\left.\mathrm{AU}^{*} \mathrm{~min}\right)$ ataupun esomeprazole (209.0 [134.8-384.8] AU*min) hampir serupa dengan pasien yang tidak mendapatkan terapi PPI $(p=0.69$ and $p=0.88)$ (Sibbing et al., 2009). Ferreiro et al., (2011) meneliti 20 pasien sehat yang diberikan klopidogrel dengan pantoprazole selama 1 minggu, kemudian dilakukan washout selama 2 - 4 minggu untuk diberikan klopidogrel saja dimana fungsi platelet dinilai menggunakan PRI/VASP. Tidak didapatkan perbedaan yang signifikan dari nilai PRI yang didapatkan pada pemberian dengan ataupun tanpa pantoprazole (Ferreiro et al., 2011).

\section{Implikasi Klinis dari Pemberian Klopidogrel Bersama dengan PPI}

Interaksi obat dianggap penting secara klinik bila berakibat meningkatkan toksisitas dan atau mengurangi efektivitas obat yang berinteraksi. Beberapa studi klinis telah dilakukan untuk melihat efek penggunaan PPI dan klopidogrel secara bersamaan.

Pada Tahun 2009 Ho et al., melakukan penelitian pada 8025 pasien yang mendapatkan klopidogrel dan PPI setelah keluar dari rumah sakit dengan melihat angka kematian atau kembalinya pasien dirawat inap akibat sindrom koroner akut. Hasilnya didapatkan peningkatan resiko kematian atau kembali dirawat inap pada pasien yang mendapatkan PPI (OR 1.25, 95\% CI: 1.11-1.41) (Ho et al., 2009).

Bhatt et al., pada tahun 2010 melakukan studi pada 3761 pasien yang dibagi menjadi 2 grup yaitu kelompok yang mendapatkan omeprazole dan kelompok yang mendapatkan placebo. Pada masingmasing pasien dimonitoring jika terjadi kejadian akibat penyakit cardiovasculer seperti revaskulariasi, infark miokard, stroke ataupun kematian akibat penyakit jantung (Bhatt et al., 2010). Penurunan perdarahan saluran cerna didapatkan pada kelompok yang mendapatkan omeprazole (hazard ratio, 0,$13 ; 95 \% \mathrm{CI}, 0,03$ to 0,$56 ; \mathrm{P}=0,001)$. Sebanyak 109 pasien mengalami kejadian kardiovaskuler dimana sebanyak $4, \%$ berasal dari kelompok yang diberikan omeprazole dan 5,7\% pada kelompok placebo. Tidak didapatkan perbedaan signifikan antara kelompok placebo dan omeprazole (HR 0,94; 95\% CI: 0,80-1,11) (Bhatt et al., 2010).

Ray et al., (2011) 20.596 melakukan studi cohort pada 20.596 pasien yang telah dipasang stent atau pasien yang mengalami sindrom koroner akut. Pada penelitian ini tidak didapatkan resiko terjadinya penyakit kardiovaskuler yang serius (HR 0,99; 95\% CI: 0,82-1,19).(Ray et al., 2011)

\section{Manajemen Strategi}

Semua obat golongan PPI secara farmakokinetik dan farmakodinamik berinteraksi dengan klopidogrel dimediasi oleh isoenzim di hati CYP P450 (CYP2C19 dan CYP3A4), namun pantoprazol (hanya dimetabolisme sedikit oleh CYP) dan rabeprazole (tidak dimetabolisme oleh CYP) dapat digunakan sebagai alternatif untuk terapi dengan omeprazole (Tantry et al., 2011). Strategi lain yang dapat dilakukan adalah mensubstitusi klopidogrel dengan golongan nonthienopyridine yang tidak dikonversi secara metabolik oleh enzim CYP P450 di hati seperti ticagrelor (Ray et al., 2011). Obat-obat pengganti golongan PPI seperti golongan $\mathrm{H} 2$ Blocker maupun antasida dapat dipertimbangkan.

\section{Referensi}

Barragan, P., Bouvier, J.-L., Roquebert, P.-O., Macaluso, G., Commeau, P., Comet, B., Lafont, A., Camoin, L., Walter, U., \& Eigenthaler, M. (2003). Resistance to thienopyridines: Clinical detection of coronary stent thrombosis by monitoring of vasodilator-stimulated phosphoprotein phosphorylation. Catheterization and Cardiovascular Interventions, 59(3), 295-302. 
Bhatt, D. L., Cryer, B. L., Contant, C. F., Cohen, M., Lanas, A., Schnitzer, T. J., Shook, T. L., Lapuerta, P., Goldsmith, M. A., Laine, L., Scirica, B. M., Murphy, S. A., \& Cannon, C. P. (2010). Clopidogrel with or without Omeprazole in Coronary Artery Disease. New England Journal of Medicine, 363(20), 1909-1917.

Cuisset, T., Frere, C., Quilici, J., Poyet, R., Gaborit, B., Bali, L., Brissy, O., Morange, P.-E., Alessi, M.C., \& Bonnet, J.-L. (2009). Comparison of Omeprazole and Pantoprazole Influence on a High 150-mg Clopidogrel Maintenance Dose. Journal of the American College of Cardiology, 54(13), 1149-1153.

Drug Information Handbook: Vol. 22th Ed. (2013). Wolters Kluwer Clinical Drug Information, Inc.

Farid, N. A., Kurihara, A., \& Wrighton, S. A. (2010). Metabolism and Disposition of the Thienopyridine Antiplatelet Drugs Ticlopidine, Clopidogrel, and Prasugrel in Humans. The Journal of Clinical Pharmacology, 50(2), 126-142.

Ferreiro, J. L., Ueno, M., Tomasello, S. D., TelloMontoliu, A., Capodanno, D., Seecheran, N., Pham, J. P., Kodali, M., Darlington, A., Desai, B., Charlton, R. K., Bass, T. A., \& Angiolillo, D. J. (2011). Impact Of Concomitant And Staggered Pantoprazole Intake On Pharmacodynamic Effects Induced By Clopidogrel. Journal of the American College of Cardiology, 57(14), E1907.

Gilard, M., Arnaud, B., Cornily, J.-C., Le Gal, G., Lacut, K., Le Calvez, G., Mansourati, J., Mottier, D., Abgrall, J.-F., \& Boschat, J. (2008). Influence of Omeprazole on the Antiplatelet Action of Clopidogrel Associated With Aspirin. Journal of the American College of Cardiology, 51(3), 256-260.

Ho, P. M., Maddox, T. M., Wang, L., Fihn, S. D., Jesse, R. L., Peterson, E. D., \& Rumsfeld, J. S. (n.d.). Risk of Adverse Outcomes Associated With Concomitant Use of Clopidogrel and Proton Pump Inhibitors Following Acute Coronary Syndrome. 8.

Ieiri, I., Kimura, M., Irie, S., Urae, A., Otsubo, K., \& Ishizaki, T. (2005). Interaction magnitude, pharmacokinetics and pharmacodynamics of ticlopidine in relation to CYP2C19 genotypic status: Pharmacogenetics and Genomics, 15(12), 851-859.

Lai, K. C., Lam, S. K., Chu, K. M., Wong, B. C. Y., Hui, W. M., Hu, W. H. C., Lau, G. K. K., Wong, W. M., Yuen, M. F., Chan, A. O. O., Lai, C. L., \& Wong, J. (2002). Lansoprazole for the Prevention of Recurrences of Ulcer Complications from Long-Term Low-Dose Aspirin Use. New England Journal of Medicine, 346(26), 2033-2038.

Ogawa, R., \& Echizen, H. (2010). Drug-Drug Interaction Profiles of Proton Pump Inhibitors: Clinical Pharmacokinetics, 49(8), 509-533.

Peters, R. J. G., Mehta, S. R., Fox, K. A. A., Zhao, F., Lewis, B. S., Kopecky, S. L., Diaz, R., Commerford, P. J., Valentin, V., \& Yusuf, S. (2003). Effects of Aspirin Dose When Used Alone or in Combination With Clopidogrel in Patients With Acute Coronary Syndromes: Observations From the Clopidogrel in Unstable angina to prevent Recurrent Events (CURE) Study. Circulation, 108(14), 16821687.

Peters, R. J. G., Mehta, S., \& Yusuf, S. (2007). Acute coronary syndromes without ST segment elevation. BMJ, 334(7606), 1265-1269.

Ray, W. A., Smalley, W. E., Hall, K., \& Daugherty, J. R. (2011). Outcomes with Concurrent Use of Clopidogrel and Proton-Pump Inhibitors: A Cohort Study. 16.

Sibbing, D., Morath, T., Stegherr, J., Braun, S., Vogt, W., Hadamitzky, M., Schömig, A., Kastrati, A., \& Beckerath, N. von. (2009). Impact of proton pump inhibitors on the antiplatelet effects of clopidogrel. Thrombosis and Haemostasis, 101(04), 714-719.

Tantry, U. S., Kereiakes, D. J., \& Gurbel, P. A. (2011). Clopidogrel and Proton Pump Inhibitors. JACC: Cardiovascular Interventions, 4(4), 365380.

Bhatt, D. L., Scheiman, J., Abraham, N. S., Antman, E. M., Chan, F. K. L., Furberg, C. D., Johnson, D. A., Mahaffey, K. W., \& Quigley, E. M. (2008). ACCF/ACG/AHA 2008 Expert Consensus 
Document on Reducing the Gastrointestinal

Risks of Antiplatelet Therapy and NSAID

Use: A Report of the American College of

Cardiology Foundation Task Force on

Clinical Expert Consensus Documents.

Circulation, 118(18), 1894-1909. 